\title{
KOMUNIKASI PEMASARAN PERUM PERHUTANI DALAM PROMOSI EKOTURISME KAWAH PUTIH
}

\author{
Dimas Satrio Wijaksono ${ }^{1}$ \\ Fakultas Komunikasi dan Bisnis, Program Studi Ilmu Komunikasi, Universitas Telkom, Bandung \\ Naskah diterima tanggal 27 Agustus, direvisi tanggal 29 Agustus, disetujui tanggal 3 September
}

\begin{abstract}
Abstrak. Pengembangan pariwisata yang dilakukan dengan baik akan mampu menarik wisatawan domestik untuk datang, begitu pula dengan Kawasan Wisata Kawah Putih yang dikelola Perum Perhutani sebagai potensi wisata menarik dan mengalami peningkatan wisatawan. Peneliti menggunakan metode penelitian kualitatif dengan paradigma konstruksivis pada penelitian ini, Berdasarkan pendekatan tersebut, maka selanjutnya pisau analisis yang penulis gunakan adalah studi kasus. Sedangkan teori pendukung yang digunakan adalah teori integrasi informasi dan perubahan sikap dengan konsep-konsep komunikasi pemasaran. Dalam penelitian ini penulis melibatkan enam orang informan.. Berdasarkan hasil penelitian menunjukan bahwa proses komunikasi pemasaran yang dilakukan Perum Perhutani dalam mempromosikan ekoturisme Kawah Putih berjalan efektif dengan menggunakan enam komponen promosi komunikasi pemasaran yaitu Advertising, Sales Promotion, Public Relation, Personal Selling, Direct Marketing dan Word Of Mouth.
\end{abstract}

Kata kunci: Komunikasi Pemasaran, Promosi, Ekoturisme.

Abstract. Well-developed tourism development will be able to attract domestic tourists to come, as well as the White Crater Tourism Area managed by Perhutani Public Corporation as an attractive tourism potential and experiencing an increase in tourists. Researchers used qualitative research methods with the constructivist paradigm in this study. Based on this approach, then the analysis that the author uses is a case study. Whereas the supporting theory used is information integration theory and attitude change with marketing communication concepts. In this study the author involved six informants .. Based on the results of the study showed that the marketing communication process carried out by Perum Perhutani in promoting ecotourism of Kawah Putih runs effectively by using six components of marketing communication promotion, namely Advertising, Sales Promotion, Public Relations, Personal Selling, Direct Marketing and Word Of Mouth.

Keywords: Marketing Communication, Promotion, Ecotourism. 


\section{PENDAHULUAN}

Perum Perhutani salah satu institusi yang dipercaya untuk mengelola hutan di Jawa memegang peran yang sangat penting dalam menjamin keberadaan kawasan hutan di Pulau Jawa dan Madura sebagai penunjang daya dukung lingkungan sosial dan ekonomi masyarakat di Jawa. Perum Perhutani saat ini mengelola sebanyak 241 objek wisata di Pulau Jawa dan Madura.

Perum Perhutani Unit III Jawa Barat dan Banten, mengelola 659.039,46 Ha hutan yang terdiri atas Hutan Lindung 229.774,74 Ha serta Hutan Produksi 429.264,71 Ha. Hutan lindung dan hutan produksi ini tersebar di 14 Kesatuan Pemangkuan Hutan (KPH) yaitu: KPH Banten, Bogor, Sukabumi, Cianjur, Purwakarta, Bandung Utara, Bandung Selatan, Garut, Tasikmalaya, Ciamis, Sumedang, Indramayu, Kuningan dan KPH Majalengka. Di Perum Perhutani Unit III Jawa Barat dan Banten juga terdapat bidang Kesatuan Bisnis Mandiri (KBM), yaitu: KBM Agroforesty, Ekowisata dan Jasa Lingkungan, KBM Industri Non Kayu dan KBM Pemasaran Kayu.

Kesatuan Bisnis Mandiri Agroforestry, Ekowisata dan Jasa Lingkungan (KBM AEJ) dibentuk berdasarkan Surat Keputusan Direksi Perum Perhutani Nomor: 199/Kpts/Dir/2009 tanggal 4 Mei 2009 tentang Struktur Organisasi yang merupakan perubahan stuktur dari Kesatuan Bisnis Mandiri Wisata, Benih dan Usaha Lain (KBM WBU). Kesatuan Bisnis Mandiri AEJ merupakan satuan unit organisasi dibawah Kantor Unit yang bertanggung jawab atas penyelenggaraan pengelolaan bisnis wisata di 11 objek lokasi wisata dari semula sebanyak 42 objek yang bertujuan guna meningkatkan pendapatan perusahaan secara mandiri.

Dengan potensi sumber daya alam wisata yang dipaparkan diatas maka dapat memberikan keuntungan bagi perusahaan serta melihat peluang yang ada saat ini, sehingga Perum Perhutani berusaha untuk menata pengelolaan objek wisatanya agar menarik minat wisatawan nasional dan mancanegara, salah satunya tempat wisata yang menjadi primadona keindahan alam Bandung Selatan adalah Kawah Putih.

Kawasan Wisata Kawah Putih dapat dijangkau dengan mudah karena memiliki aksesibilitas yang memadai dan mudah dijangkau dari kota Bandung. Waktu tempuh menuju lokasi adalah sekitar 1 jam perjalanan normal dari Ibukota Kabupaten Bandung. Kondisi jalan pada umumnya baik dan beraspal sehingga dapat dicapai dengan kendaraan dua maupun roda empat. Jarak tempuh dari Bandung $47 \mathrm{~km}$. Panorama yang ditawarkan oleh Kawah Putih memang sangat indah akan tetapi tidak sampai disitu saja. Ternyata di area kawah putih masih ada jenis-jenis satwa yang dilindungi undang-undang, yang hidup di hutan wisata kawah Putih 
dan desa Barusel (desa terdekat dengan kawah) diantaranya adalah Surili (Presbytis comatecomata), Macan Tutul (Phantera pardus), Lutung (p.cristata) dan Jalarang (Ratufa Bicolor), Berbagai jenis burung yang terdapat di kawasan ini antara lain ayam hutan (Gallus Gallus), burung sepah gunung (Pericrocotus Miniatus) dan Puyuh gongong (Arborophila Javanica). Sebelas dari 72 jenis burung yang terdapat di sekitar kawasan kawah Putih merupakan burung yang dilindungi, diantaranya burung elang hitam (Ictinaetus malayensis), elang ruyuk (Spilornis cheela), Cerecet (Psaltria exilis), alap-alap (iFalco pregrenus), Kipasan merah (Rhipidura phoenicurai), Burung madu gunung (aethopyga mystacalis), Burung madu kuning (Nectarinia jugularis), Puyuh gongong (Arborophila javanica), Burung Kuda (garullax rufifrons) dan Opioropior (Lophozosterops javanicus).

Sektor wisata alam khususnya Kawah Putih mengalami trend positif, dapat dilihat bahwa objek wisata alam sangat diminati wisatawan baik wisatawan domestik maupun mancanegara. Hal ini dikarena ada kejenuhan dengan objek wisata buatan yang terus menjamur di kota-kota besar yang ada. Ini merupakan salah satu peluang wisata yang bisa KBM AEJ Perum Perhutani jual. Potensi wisata natural Kawah Putih yang dimiliki oleh KBM AEJ tidak kalah menariknya dengan wisata alam lainnya. Selama ini WW Kawah Putih memang menjadi tujuan utama pariwisata di daerah Bandung Selatan disamping objek wisata alam lainnya.

Namun dengan mencermati perkembangan trend wisata nusantara dan mancanegara yang akhir-akhir ini menggejala, dapat dilihat bahwa potensi obyek wisata natural atau alami bisa diintensifkan pengelolaannya. Sekarang ini turis nusantara dan mancanegara tidak lagi tertarik dengan wisata yang mewah, minat turis asing dan domestik lebih tertuju kepada obyek wisata yang alami seperti ecotourism (ekowisata). Sebanyak 28\% pelanggan menyukai obyek wisata pantai, 48\% pelanggan menyukai obyek wisata pegunungan, dan $14 \%$ pelanggan menyukai hutan sebagai tempat wisata. Hal ini disebabkan suhu di kota besar yang semakin hari semakin panas, sehingga destinasi wisata yang memiliki hawa sejuk semakin diminati pula. Persepsi pelanggan mengenai wisata Pegunungan dan Hutan juga menjadi faktor yang berpengaruh terhadap grafik. Banyak dari pelanggan yang menganggap wisata hutan sebagai wisata pegunungan. 


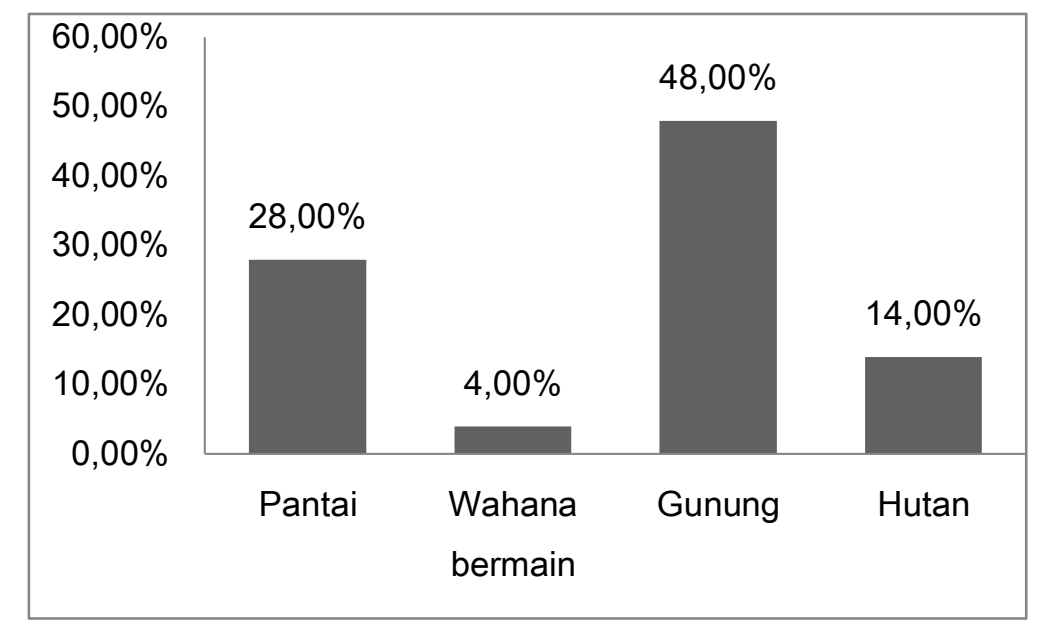

Gambar 1. Grafik Pelanggan Berdasarkan Obyek Wisata

Sumber : Intermal Perum Perhutani KBM AEJ 2010

Animo masyarakat berkunjung ke objek wisata pegunungan di Bandung Selatan, seperti wisata pantai, wahana bermain, gunung, hingga wisata panorama seperti Kawah Putih, masih tinggi. Selain wisatawan domestik, jumlah wisatawan asing yang mengunjungi objek wisata di Bandung Selatan diprediksi mencapai sekitar 50.000 orang. Kenaikan terbesar jumlah pengunjung terjadi saat libur Lebaran, dengan lonjakan mencapai 100-200 persen. Objek wisata Kawah Putih masih menjadi primadona wisata di Bandung Selatan. Tak hanya didominasi warga Bandung, terutama warga Jakarta. Berdasarkan pemantauan, tampak kendaraan berplat B memadati sarana parkir di kawasan wisata Kawah Putih, Ciwidey Kabupaten Bandung. Dengan kondisi animo pengunjung yang meningkat setiap weekendnya, KMB AEJ dapat melihat peluang yang besar untuk mendorong objek wisata Kawah Putih agar terus dikunjungi calon pengunjung.

Berwisata mengunjungi objek wisata alam merupakan kebutuhan psikologis yang bersifat struktural sebagai bagian dari pemenuhan kebutuhan aktualisasi diri dan menghabiskan waktu luang. Kompetisi yang cukup ketat diantara pengelola objek wisata dalam memasarkan produknya ditandai oleh gencarnya komunikasi pemasaran yang dilakukan oleh para pengelola wisata lainnya. Komunikasi pemasaran merupakan kegiatan pemasaran produk objek wisata dengan menggunakan teknik-teknik komunikasi yang bertujuan untuk memberikan informasi pada orang banyak agar tujuan pengelola tercapai yaitu terjadinya peningkatan pengunjung, salah satunya dengan cara membuat brosur paket wisata seperti dapat dilihat pada Gambar 1.2 


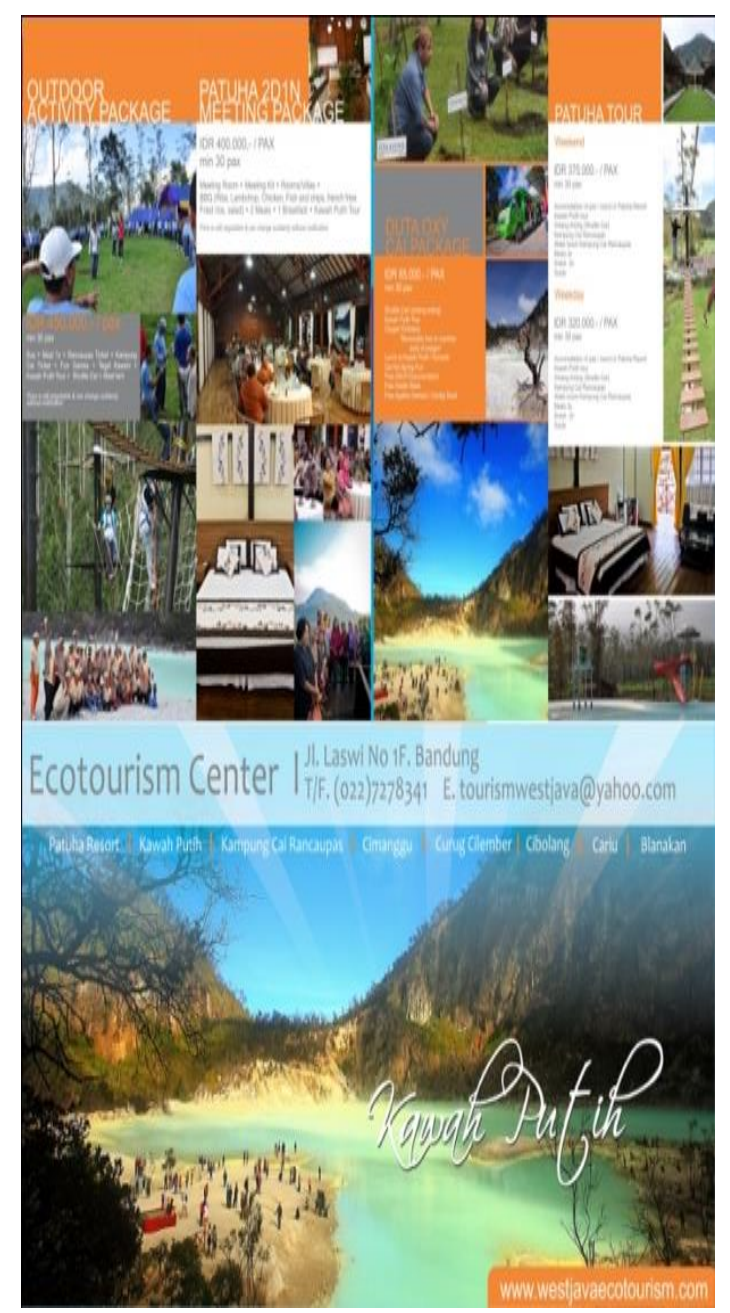

Sumber: Internal Perum Perhutani KBM AEJ 2012

Gambar 1. Brosur Paket Wisata Kawah Putih

Salah satu media promosi yang digunakan adalah brosur paket-paket objek wisata yang dikelola KBM AEJ. Dengan adanya media brosur sebagai informasi Kawah Putih, membuat kenaikan pengunjung pada tahun 2012 dibandingkan dengan tahun 2011 yang belum menggunakan media promosi brosur seperti dapat dilihat pada laporan pendapatan dan biaya lokasi obyek 2011 - 2012 KBM jasa lingkungan dan produk lain Perum Perhutani Unit III Jawa Barat dan Banten pada Gambar 1.3. 


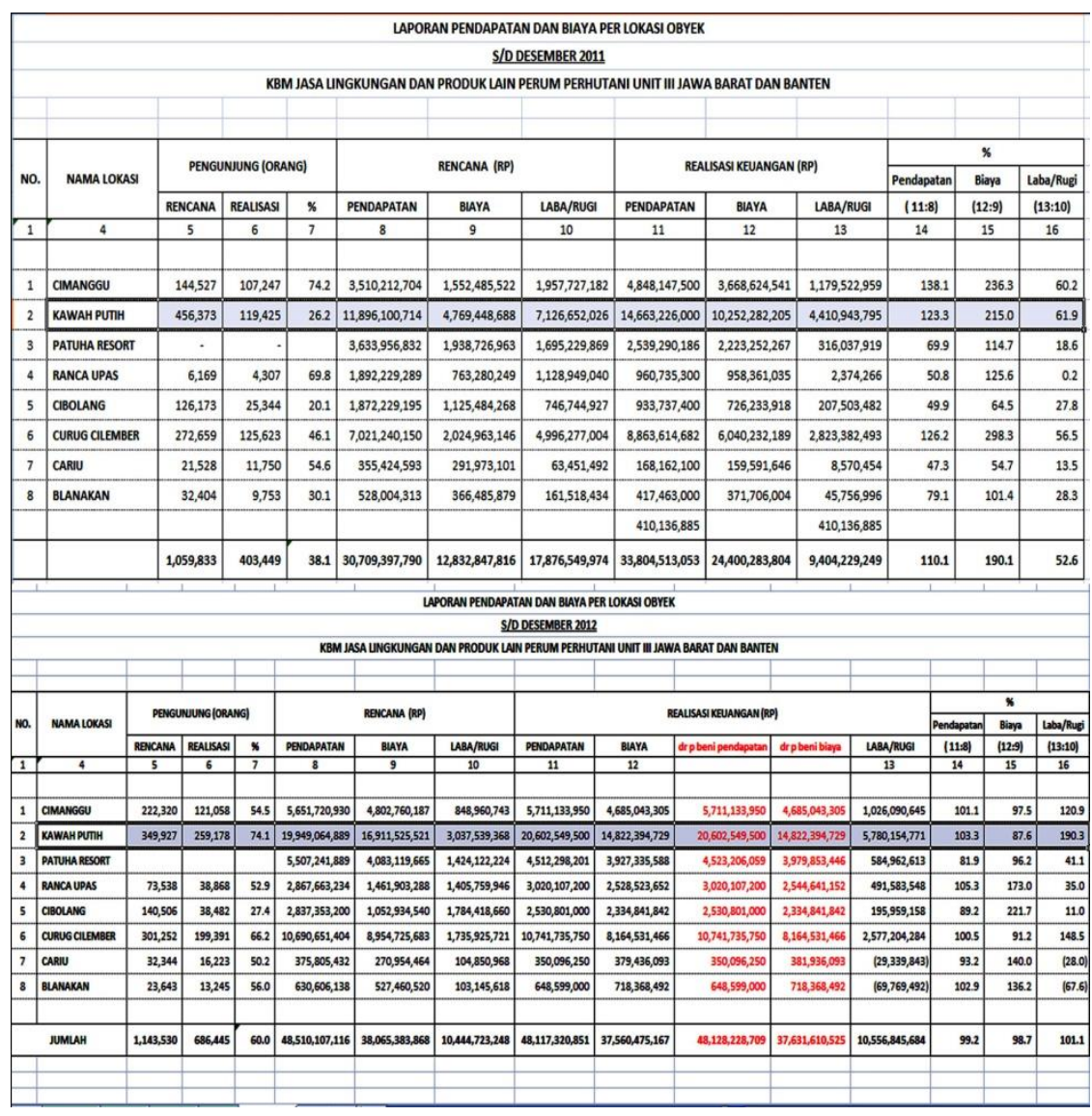

Sumber: Perum Perhutani Unit III Jawa Barat dan Banten

Gambar 2. Laporan Pendapatan dan Biaya Lokasi Obyek 2011- 2012 (KBM Jasa Lingkungan dan Produk Lain)

Melihat potensi keindahan alam yang dimiliki oleh Kawah Putih, Perum Perhutani berusaha untuk mengembangkan Wana Wisata Kawah Putih sejak 1991, yang tentunya tidak luput dari komunikasi pemasaran yang merupakan kegiatan komunikasi yang penting antara pihak pengelola sebagai produsen dan konsumen dengan menggunakan berbagai media, dengan harapan agar komunikasi dapat mempengaruhi keputusan minat berkunjung wisatawan. Di lain pihak perubahan perilaku konsumen akan menyebabkan pengelola harus memperbaharui secara terus menerus komunikasi pemasaran yang telah ditetapkan.

Ketepatan suatu komunikasi pemasaran bagi produk objek wisata menjadi sangat penting karena berperan dalam menyampaikan informasi tentang keunggulan produk yang ditawarkan. Masalah yang dihadapi saat ini dalam bidang pemasaran untuk kawasan Wana Wisata Kawah Putih adalah tidak adanya pengembangan komunikasi pemasaran yang dilakukan KBM AEJ disebabkan karena keterbatasan informasi mengenai perilaku dan keinginan konsumen yang menjadi target pasarnya. Di lain pihak pengembangan komunikasi pemasaran akan berpengaruh pada aspek pembiayaan yang harus dikeluarkan oleh perusahaan seperti dapat dilihat pada deskripsi data di bawah ini: 


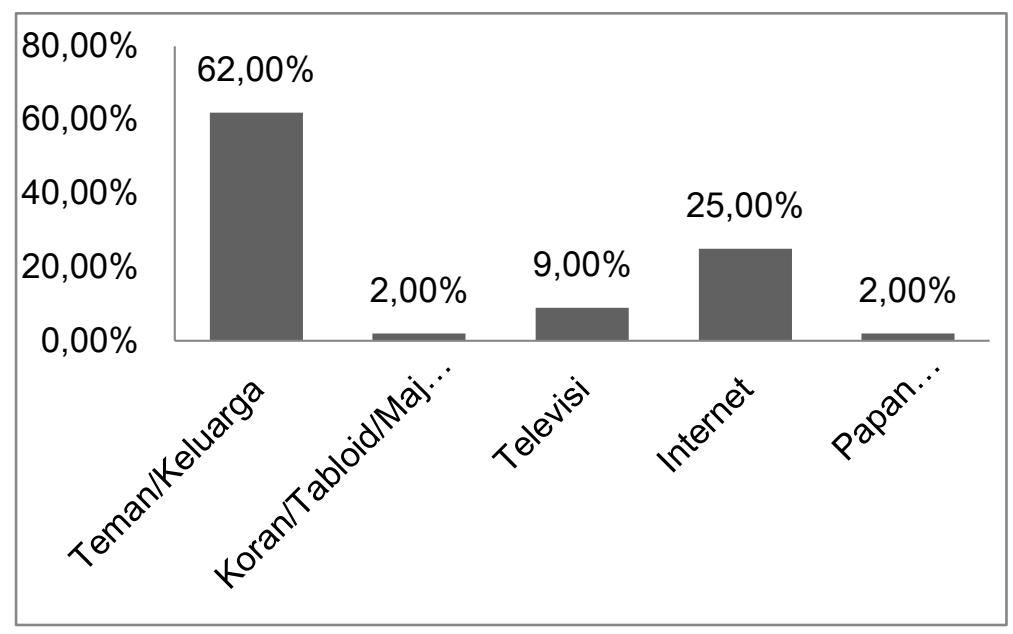

Sumber : Internal Perum Perhutani KBM AEJ 2012

Gambar 3. Perilaku Pelanggan Berdasarkan Sumber Informasi

Kegiatan pemasaran dengan menggunakan sejumlah media dan berbagai saluran yang dapat dipergunakan dengan harapan terjadinya tiga tahapan perubahan, yaitu : perubahan pengetahuan, perubahan sikap, dan perubahan tindakan yang dikehendaki. (Soemanagara, 2008:4). Sehingga dapat dipahami bahwa media merupakan salah satu saluran yang tepat untuk dapat menginformasikan mengenai sebuah produk sehingga konsumen akan mendapatkan suatu informasi yang sifatnya dapat mengubah persepsi dan pengetahuan yang lebih, untuk kebutuhan yang diinginkan. Gabungan semua unsur dalam bauran pemasaran merek, yang memfasilitasi terjadinya pertukaran dengan menciptakan suatu arti yang disebarluaskan kepada pelanggan atau kliennya (Shimp, 2003:4). Sehingga pertanyaan penelitian dalam rumusan penelitian ini adalah bagaimana komunikasi pemasaran yang dilakukan Perum Perhutani dalam Mempromosikan Ekoturisme Kawah Putih di Ciwidey Kabupaten Bandung.

\section{METODE PENELITIAN}

Metode penelitian adalah teknik - teknik spesifik dalam penelitian. Sebagian orang menganggap bahwa metode penelitian terdiri dari berbagai teknik penelitian dan sebagian lagi menyamakan metode penelitian dengan teknik penelitian. Tetapi yang jelas, metode atau teknik penelitian apapun yang kita gunakan, misalnya apakah kuantitatif atau kualitatif, haruslah sesuai dengan kerangka teoritis yang kita asumsikan (Mulyana, 2001:146). Metode penelitian yang digunakan oleh peneliti untuk mengkaji masalah komunikasi pemasaran ekoturisme kawah putih ini adalah metode penelitian kualitatif. Karena Metode penelitian kualitatif adalah metode penelitian yang digunakan untuk meneliti pada kondisi obyek yang alamiah (sebagai lawannya 
adalah eksperimen) dimana peneliti adalah sebagai instrument kunci, teknik pengumpulan data dilakukan secara trianggulasi (gabungan), analisis data bersifat induktif, dan hasil penelitian kualitatif lebih menekankan makna dari pada generalisasi (Sugiono, 2013:1). Berdasarkan hal tersebut maka dapat dipaparkan bahwa metode penelitian kualitatif itu dilakukan secara intensif, peneliti ikut berpartisipasi lama dilapangan, mencatat secara hati-hati apa yang terjadi, melakukan analisis reflektif terhadap berbagai dokumen yang ditemukan di lapangan, dan membuat laporan penelitian secara mendetail

\section{HASIL PENELITIAN DAN PEMBAHASAN}

Berdasarkan hasil penelitian menunjukan bahwa (1) Proses komunikasi pemasaran yang dilakukan Perum Perhutani dalam mempromosikan ekoturisme Kawah Putih berjalan efektif dengan menggunakan enam komponen promosi komunikasi pemasaran yaitu Advertising, Sales Promotion, Public Relation, Personal Selling, Direct Marketing dan Word Of Mouth. (2) Alasan Perum Perhutani memilih komunikasi pemasaran dalam mempromosikan ekoturisme, karena: a) Advertising, informasi tersebar mencuri perhatian wisatawan. b) Sales Promotion, biaya terukur menjadi nilai tambah dalam paket promosi nilai insentif mediator. c) Public Relation, informasi dan mediator internal wisatawan, sponsor ship untuk menjaga citra positif perusahaan. d) Personal Selling, membujuk wisatawan langsung merasakan respon wisatawan. e) Direct Marketing, posting catalog mendapatkan tanggapan langsung wisatawan melalui internet. f) Word Of Mouth, promosi hemat menggunakan "Talker" menceritakan pengalaman bwisata positif, untuk mendapatkan wisatawan baru. (3) Kendala Perum Perhutani dalam proses komunikasi pemasaran meningkatkan promosi kawasan wisata Kawah Putih terdiri dari kendala berupa: a) Advertising, majalah internal terbatas, brosur mudah dibuang wisatawan. b) Sales Promotion, pameran tidak semua wisatawan tercapai. c) Public Relation, sponshorship makanan mengotori lokasi, aktivitas public relations menguras biaya. d) Personal Selling, wisatawan terlayani tidak banyak proses komuikasi menyita waktu. e) Direct Marketing, internet tidak menjangkau semua daerah. f) Word Of Mouth, agent/talker attitude tidak baik info negatif, kompetitor memberikan insentif. 


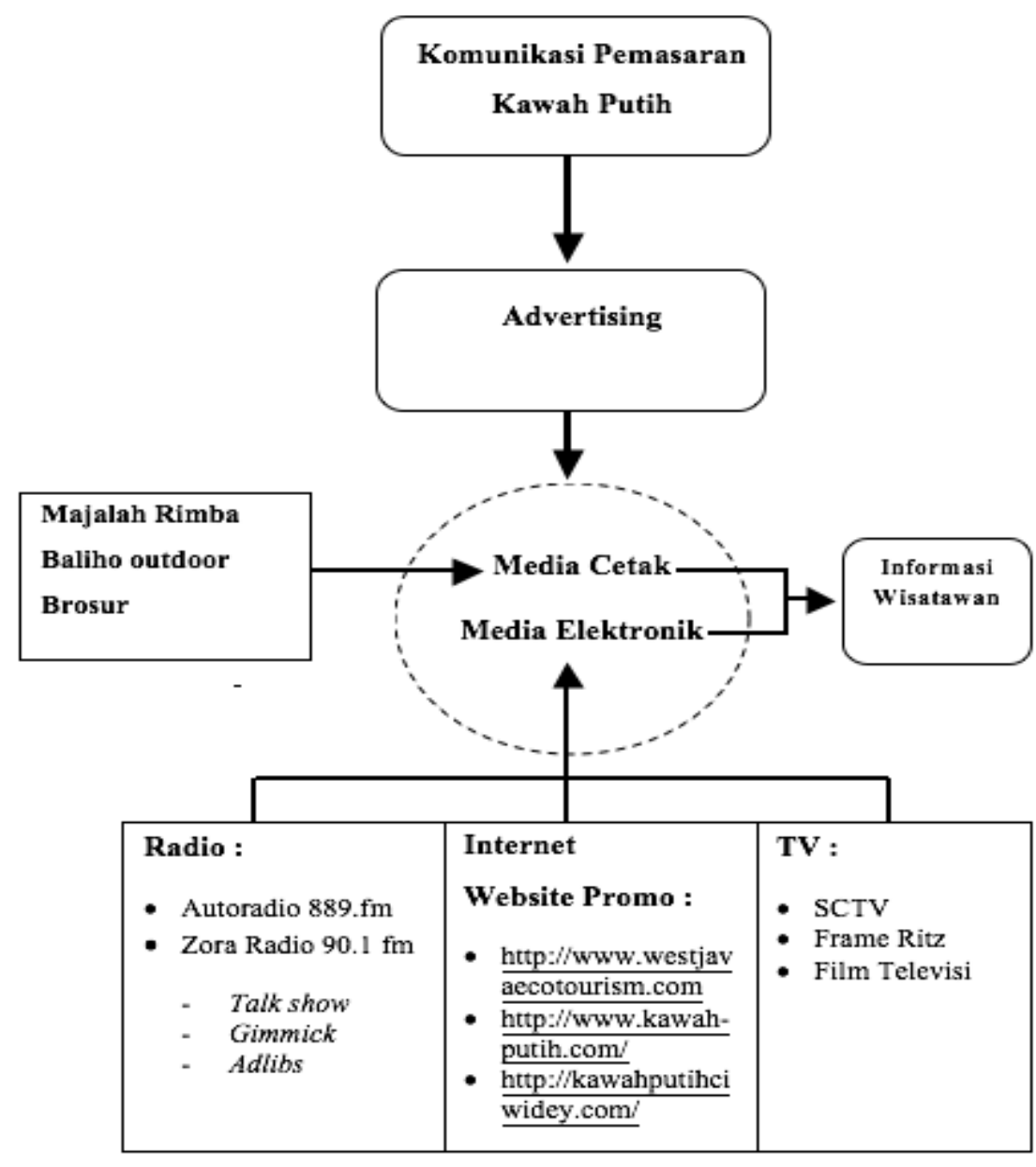

Sumber : Olahan Peneliti

Gambar 4. Advertising Sebagai Promosi Pemasaran Kawah Putih

Advertising, dalam promosi ekoturisme Kawah Putih menggunakan media cetak dan media elektronik sebagai pusat pemberian informasi kepada wisatawan. Penggunaan media tersebut dilakukan melalui radio, internet dan televisi. 


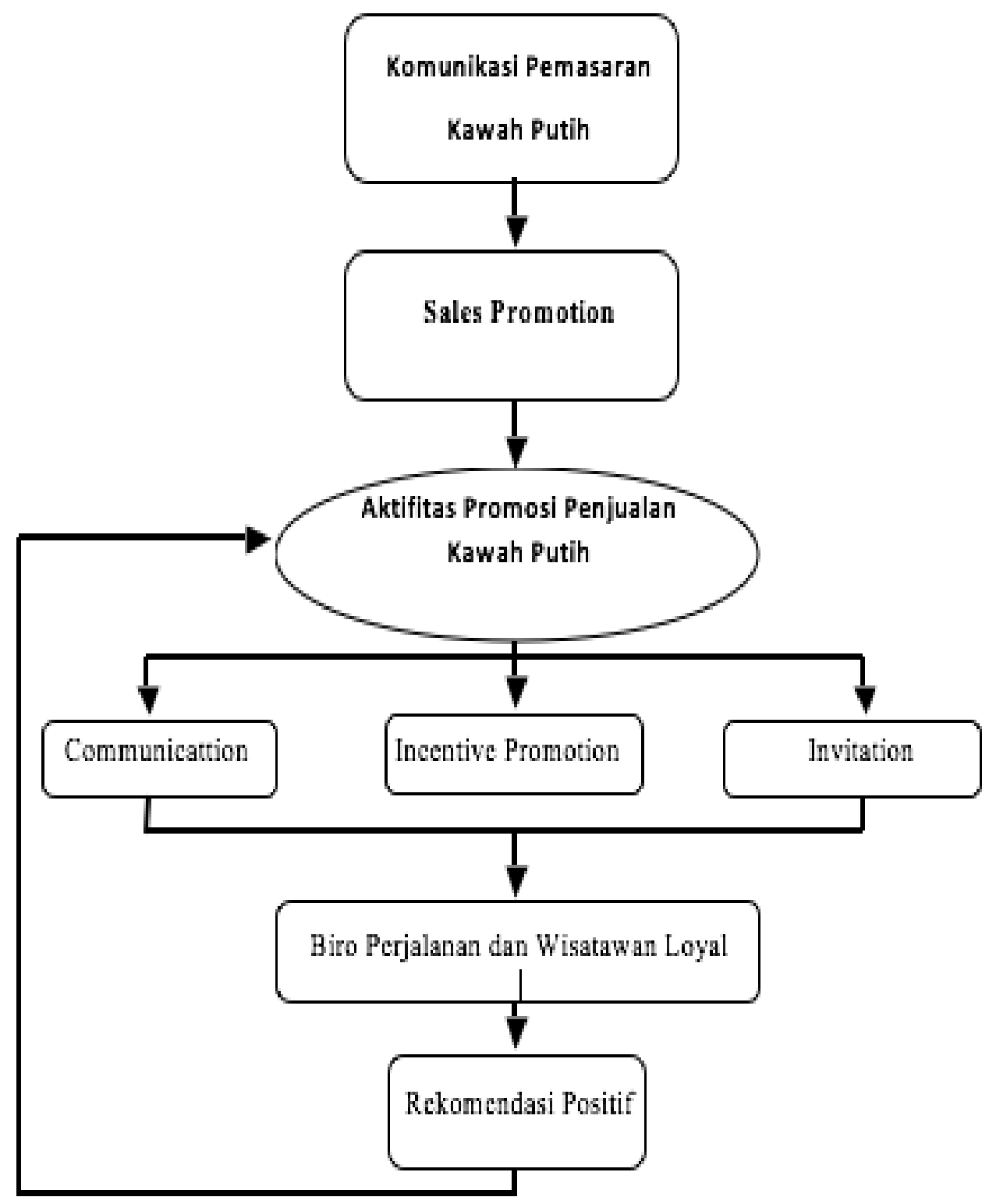

Sumber : Olahan Peneliti

Gambar 5. Sales Promotion Sebagai Promosi Pemasaran Kawah Putih

Sales Promotion, dalam promosi ekoturisme Kawah Putih menggunakan aktifitas promosi penjualan sebagai tahapan untuk mendapatkan wisatawan yang berdampak kepada rekomendasi positif untuk berkunjung melalui biro perjalanan dan wisatawan yang loyal. 


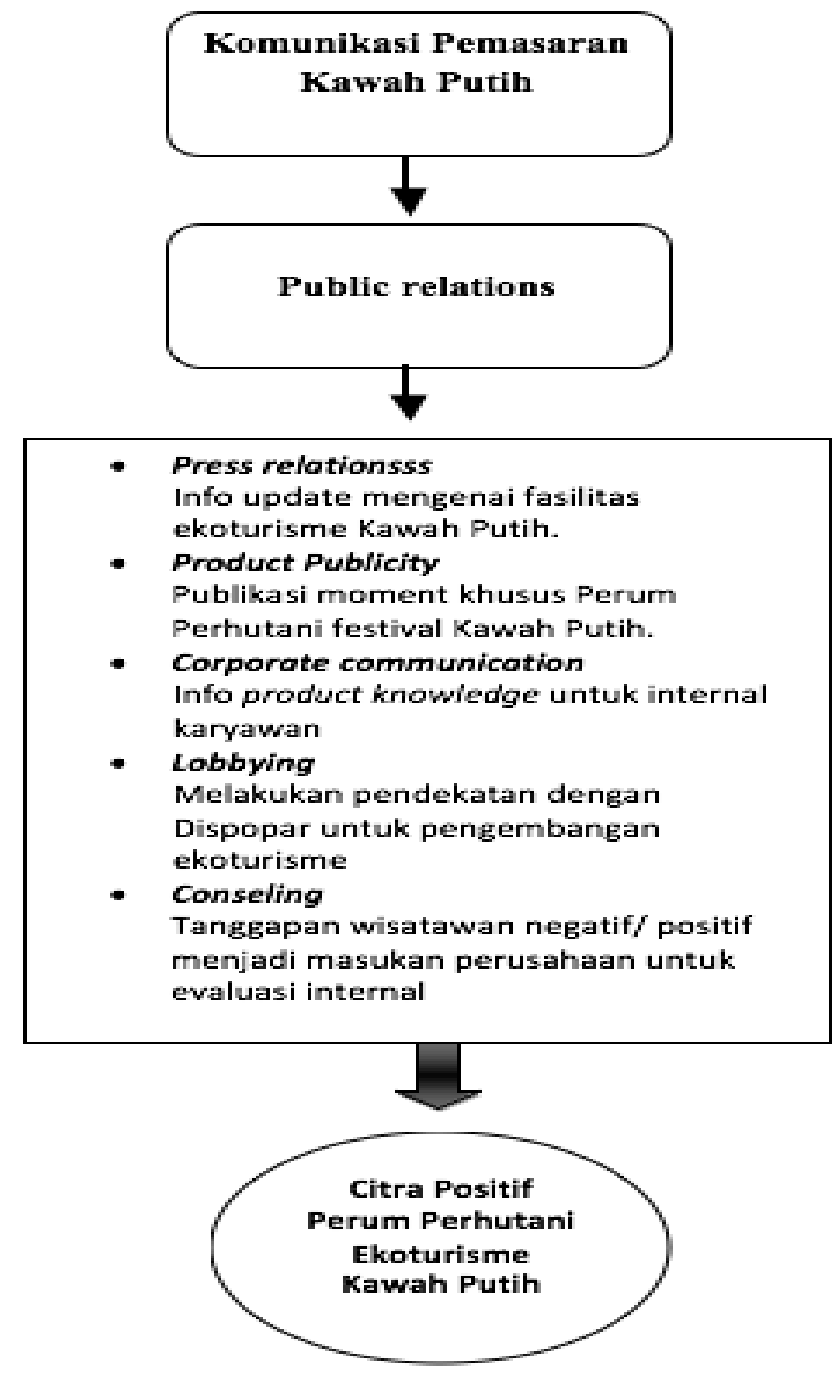

Sumber : Olahan Peneliti

Gambar 6. Public Relations sebagai Promosi Pemasaran Kawah Putih

Public Relations, dalam promosi ekoturisme Kawah Putih digunakan untuk menciptakan citra positif Kawah Putih didukung dengan selalu meng update informasi, publikasi event khusus, product knowledge karyawan, lobbying pemerintahan setempat dan conseling sebagai masukan evaluasi untuk menciptakan perubahan yang positif dalam hal memberi kepuasan berkunjung bagi wisatawan. 


\section{Personal Selling Kawah putih}

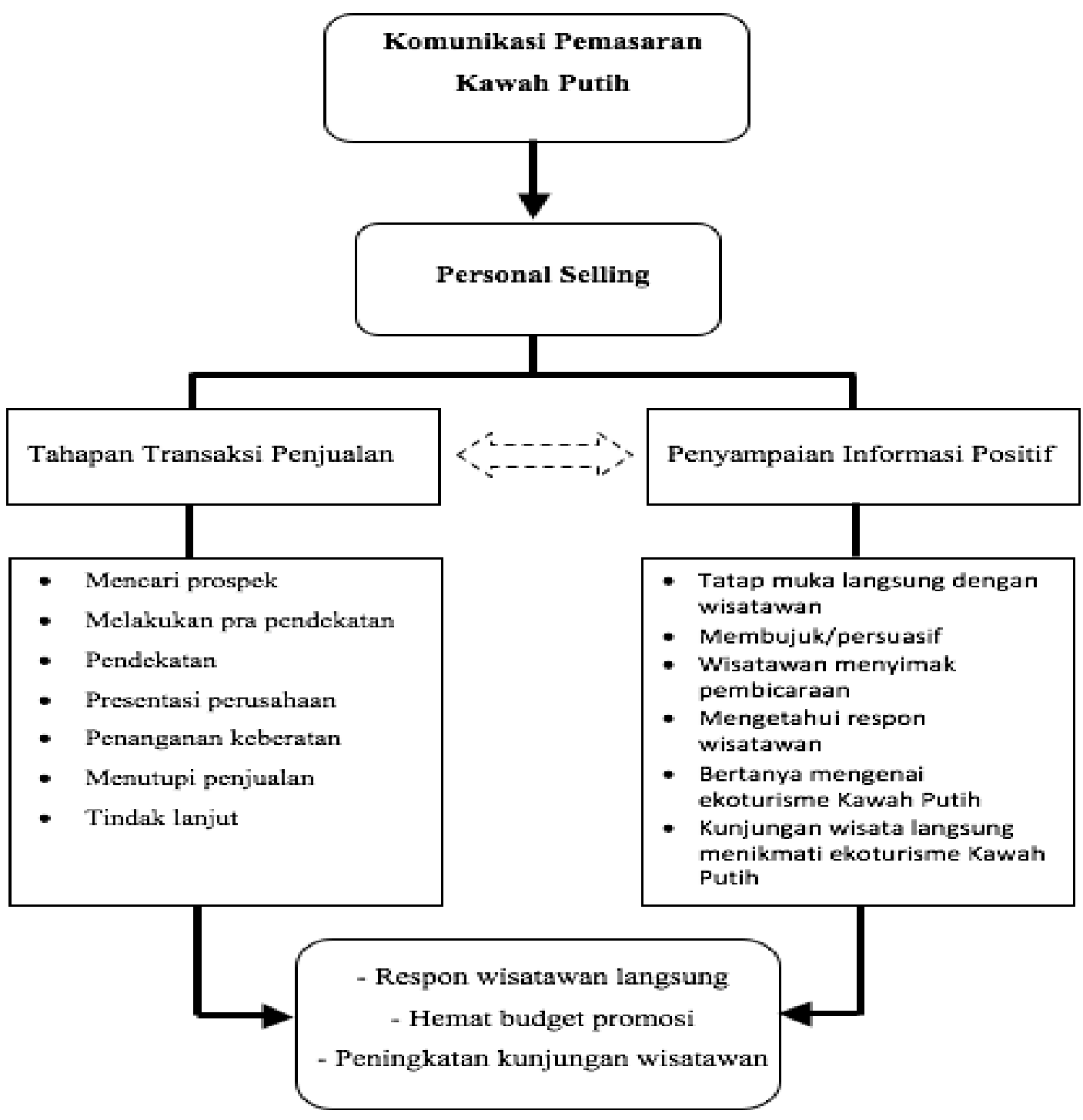

Sumber : Olahan Peneliti

Gambar 7. Personal Selling Kawah Putih

Personal Selling, dalam promosi ekoturisme Kawah Putih menggunakan tahapan transaksi penjualan dan penyampaian informasi positif digunakan untuk mendapatkan respon wisatawan langsung serta budget promosi cukup hemat yang akhirnya peningkatan kunjungan wisatawan. 


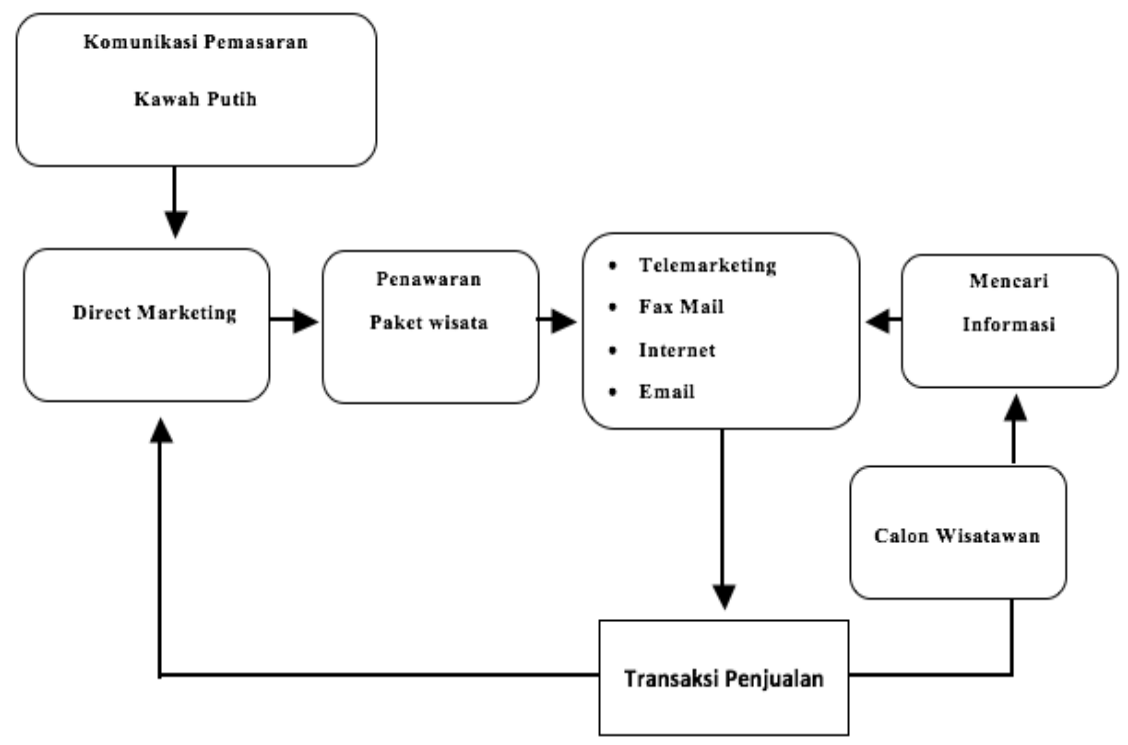

Sumber : Olahan Peneliti

Gambar 7. Direct Marketing Kawah Putih

Direct Marketing, dalam promosi ekoturisme Kawah Putih digunakan sebagai penawaran secara langsung dengan wisatawan melalui media fax maupun email yang berisi content paket maupun informasi yang dibutuhkan wisatawan.

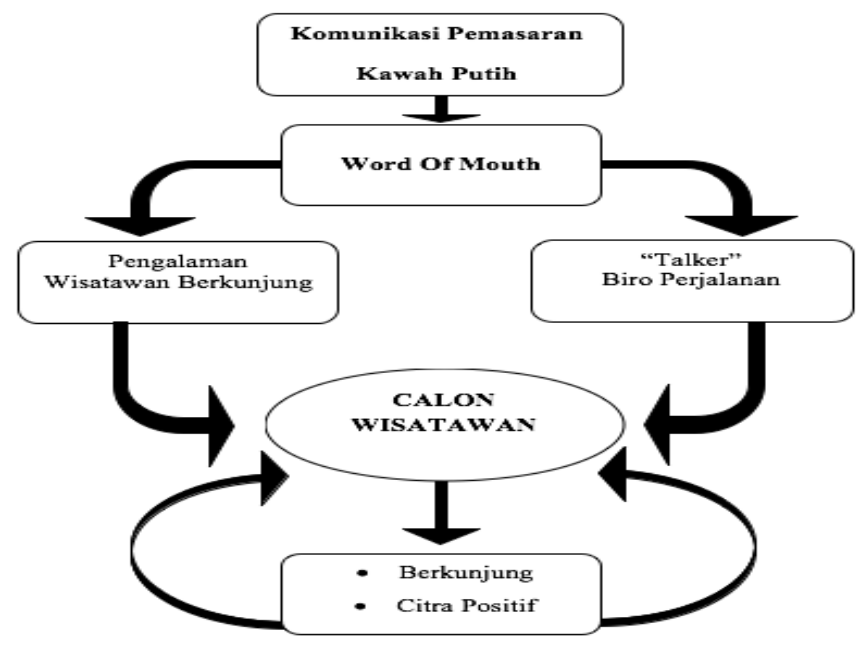

Sumber : Olahan Peneliti

Gambar 8. Word of Mouth Kawah Putih

Word Of Mouth, dalam promosi ekoturisme Kawah Putih merupakan kegiatan yang efektif digunakan oleh Perum Perhutani, dengan penggunaan pengalama wisatawan yang pernah berkunjung dan biro perjalanan wisata sebagai "talker" dengan menceritakan sisi positif ekoturisme Kawah Putih dapat mempengaruhi calon wisata lainnya untuk berkunjung. 
Aktifitas yang dilakukan pihak Perum Perhutani untuk mempromosikan ekoturisme dengan menggunakan media atau alat yang berkaitan dengan unsur diatas berdampak pada peningkatan jumlah wisatawan dari tiap tahunnya sesuai dengan apa yang dijelaskan oleh para informan.

\section{SIMPULAN}

Perkembangan usaha pariwisata sangat meningkat dengan adanya penggunaan pemasaran khusus ditiap perusahaan pengelola ekoturisme. Seiring banyaknya wisatawan yang melakukan kunjungan wisata khusunya ekoturisme menjadikan para pelaku usaha dibidang jasa pariwisata menjadi lebih inovatif untuk melakukan komunikasi pemasaran. Hal ini membuat calon peneliti selanjutnya untuk mencoba melakukan penelitian dengan menggunakan bauran komunikasi pemasaran yang berbeda dari yang dilakukan penulis sekarang.

Penelitian mengenai komunikasi pemasaran Perum Perhutani dalam promosi ekoturisme yang dilakukan oleh penulis adalah penelitian metodologi kualitatif dengan metode studi kasus yang meneliti mengenai sebuah kasus dari sebuah fenomena yang ada dilapangan. Hal yang dapat dilakukan oleh calon peneliti selanjutnya, adalah mencoba meneliti dengan menggunakan metode yang berbeda maupun teori - teori lainnya yang dapat mendukung penelitian sehingga mendapatkan hasil yang berbeda dari pemikiran yang baru.

Dalam penggunaan bauran komunikasi pemasaran Perum Perhutani untuk mempromosikan ekoturisme Kawah Putih yang terdiri dari Advertising, Sales Promotion, Public Relations, Personal Selling, Direct Marketing dan Word Of Mouth sudah dilakukan dengan cukup baik tetapi perlu mendapatkan perhatian khusus dibagian advertising yang berupa ide kreatif yang ditempatkan pada tempat potensial dengan menggunakan jasa advertising consultant memang akan membutuhkan biaya yang cukup lumayan tetapi dampak yang didapatkan bisa dirasakan untuk tahun selanjutnya. Alasan penggunaan bauran komunikasi pemasaran Perum Perhutani terlihat menitik beratkan pada word of mouth karena dapat dikatakan cukup hemat dalam biaya dan simple dalam pelaksanaannya tetapi hal ini bisa menjadi ancaman untuk Kawa Putih ketika "talker" biro perjalanan tidak dibina dengan baik karena dikhawatirkan akan memberikan informasi negatif yang berdampak pada citra Kawah Putih sebagai ekoturisme wisata, sebaiknya menggunakan kontrak khusus dengan beberapa biro perjalanan yang potensial untuk mempertahankan wisatawan yang loyal untuk mencapi peningkatan wisatawan yang lahir dari talker dengan citra yang positif. 
Kendala yang dialami Perum Perhutani dalam mempromosikan Kawah Putih memang mengalami hambatan dari segi apapun tetapi setelah peneliti lihat kendala ini terjadi karena kurang adanya monitoring khusus yang dilakukan oleh Perum Perhutani sebagai pengelola ekoturisme Kawah Putih, sebaiknya selalu di adakan forum group discussion dari berbagai macam divisi yang bertujuan untuk evaluasi hambatan apa saja yang didapatkan ketika dilapangan yang nantinya melakukan diskusi untuk dipecahkan bersama dan mendapatkan keputusan bersama.

\section{DAFTAR PUSTAKA}

\section{Buku:}

Perum Perhutani. 2012. Brand Guidelines Logo Kita. Perum Perhutani Unit III Jawa Barat dan Banten

Perum Perhutani. 2010. Company Profile Perum Perhutani KBM AEJ. Perum Perhutani Unit III Jawa Barat dan Banten

Mulyana, Deddy. 2001. Metodologi Penelitian Kualitatif, Bandung: PT. Remaja Rosdakarya Sugiyono. 2013. Memahami Penelitian Kualitatif, Bandung: CV. Alfabeta.

Yulianita, Neni. 2001. Dasar-dasar Public Relations, Bandung: Lab. Multimedia Fikom Unisba.

\section{Artikel Internet:}

Marketing Plan Perum Perhutani Unit III Jabar \& Banten. 2012. http://bumn.go.id/perhutani/halaman/170 